\title{
RISKY NATURE OF DEVELOPMENT THE ELECTRICITY INDUSTRY OF RUSSIA
}

Albina D. Khairullina ${ }^{1}$

Azat R. Safiullin ${ }^{2}$

Aigul I. Sabirova ${ }^{3}$

Asiya M. Ilyasova $^{4}$

\begin{abstract}
The electric power industry is one of the basic sectors of the economy of any country, which affects the development of both its individual components and the entire system as a whole. This article analyzes the risk nature of the electricity industry in the Russian Federation and the Republic of Tatarstan. In order to identify features of the organization's risk management, PJSC RusHydro was considered as an example. The article reflects the degree of influence of the TOP-10 business risks, discloses a scoring rating of the investment attractiveness of industries, as well as an example of the use of the risk radar using the example of a company supplying electricity and risks to the Russian Federation. The systematization of data and the dialectical approach made it possible to
\end{abstract}

conclude that the energy sector of the Russian Federation is extremely strongly influenced by energy crises and radical greening. In turn, radical greening is manifested in the tightening of legislative and tax requirements in the field of environmental protection, as well as in the change in consumer demand towards more environmentally friendly products. An analysis of the measures being implemented at the level of the Russian Federation led to the conclusion that the private investments that were attracted as a result of this process significantly increased the size of the reserve capacity of the Russian energy system.

Keywords: electric power industry, risky nature of the industry, organization risk management system

\footnotetext{
${ }^{1}$ Kazan Federal University. e-mail: aigylkinyes@ mail.ru. Tel: +79179350191

${ }^{2}$ Kazan Federal University. e-mail: aigylkinyes@mail.ru. Tel: +79179350191

${ }^{3}$ Kazan Federal University. e-mail: aigylkinyes@mail.ru. Tel: +79179350191

${ }^{4}$ Kazan Federal University. e-mail: aigylkinyes@mail.ru. Tel: +79179350191
} 


\section{Introduction}

Enterprises operating in the electric power industry are subject to various types of risks. In this regard, we consider it relevant to conduct an analysis of the riskiness of the electric power industry, thereby identifying the most dangerous risks in this area, and also to determine the existing methods of influencing them.

\section{Methods}

In order to identify the degree of riskiness of the electric power industry, first of all, it is necessary to highlight a number of the most common risks:

- violations of legislative and regulatory requirements;

- $\quad$ volatile commodity prices and access to fuel supplies on a longterm basis and at competitive prices;

- $\quad$ state participation in the electric power industry and the fuel and energy complex;

- $\quad$ vague policies to combat climate change and fines for greenhouse gas emissions;

- $\quad$ significant changes in the cost and availability of capital;

- $\quad$ implementation of capital construction projects;
- economic instability and the resulting short-term drop in energy demand;

- lack of qualified

personnel;

- physical and moral depreciation of generating capacities and energy supply systems;

- planning issues and the risk of public opposition [10].

The study conducted by Ernst \& Young regarding the riskiness of industries [6] is also seen as useful. The result was a list of TOP-10 business risks. In this report, the company assessed 12 different industries and colorfully determined the degree of influence of each risk on the industry (Fig. 1).

Also, during the assessment of the degree of riskiness of the electric power industry, it was revealed that such indicators as the investment attractiveness of the industry, the number of legal entities-bankrupt of this industry, the share of bankrupt in their total number over several periods play a significant role. 


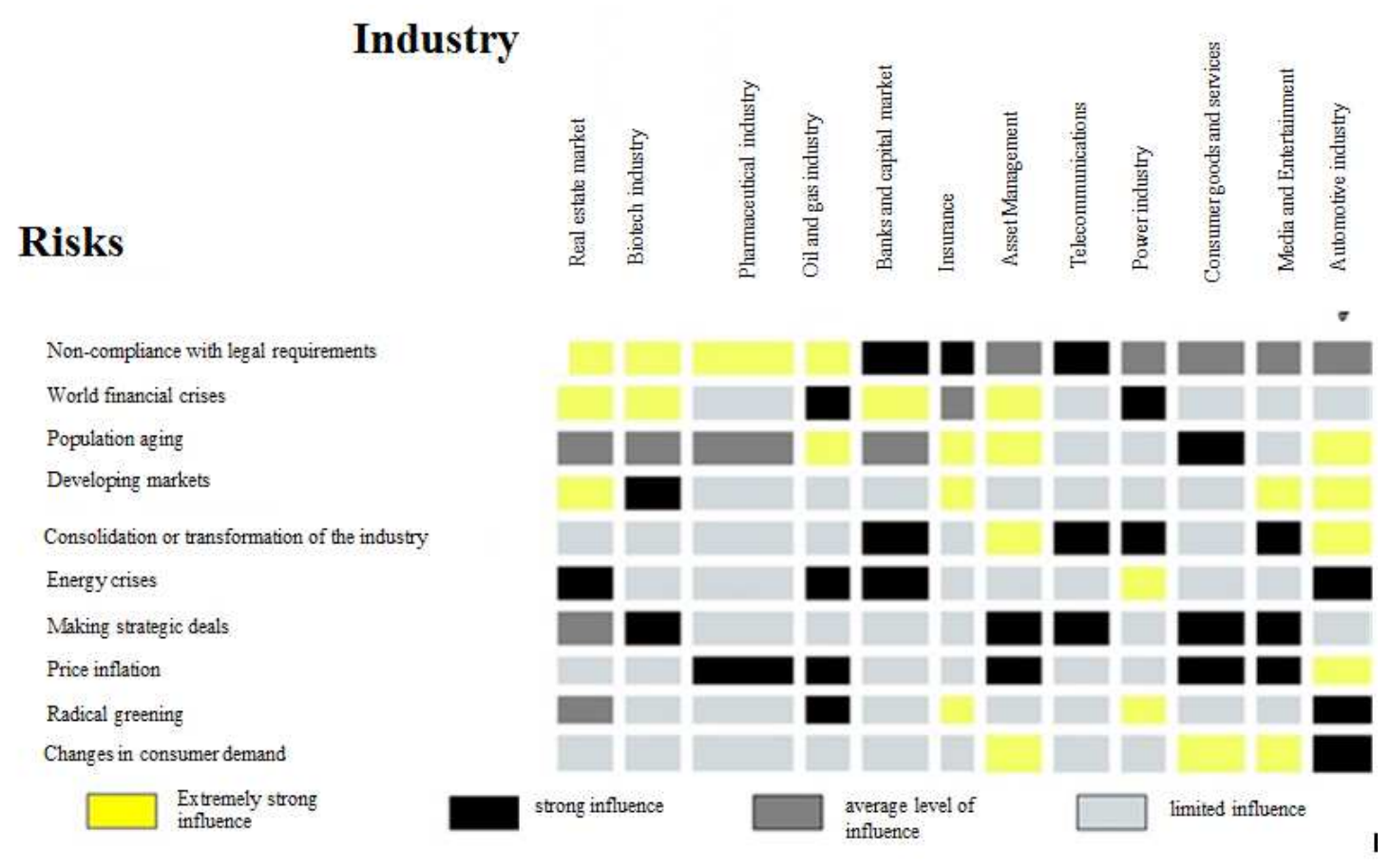

Fig. 1. The degree of influence of the TOP-10 business risks [6].

As for the investment attractiveness of the electric power industry, the analysis conducted by the oil production, metallurgy, analysts of the FINAM company [3] may turn out to be useful here. In the course of this study, the investment attractiveness of 13 sectors of the world economy was assessed: light industry, food industry, engineering, oil refining, electric power, timber, coal, chemical, communications, gas, retail. The assessment was carried out according to a point-rating system - from 0 to 50 points (Fig. 2).

The next factor - the bankruptcy of companies - may also indicate the riskiness of a particular industry. 


\section{Investment activity}

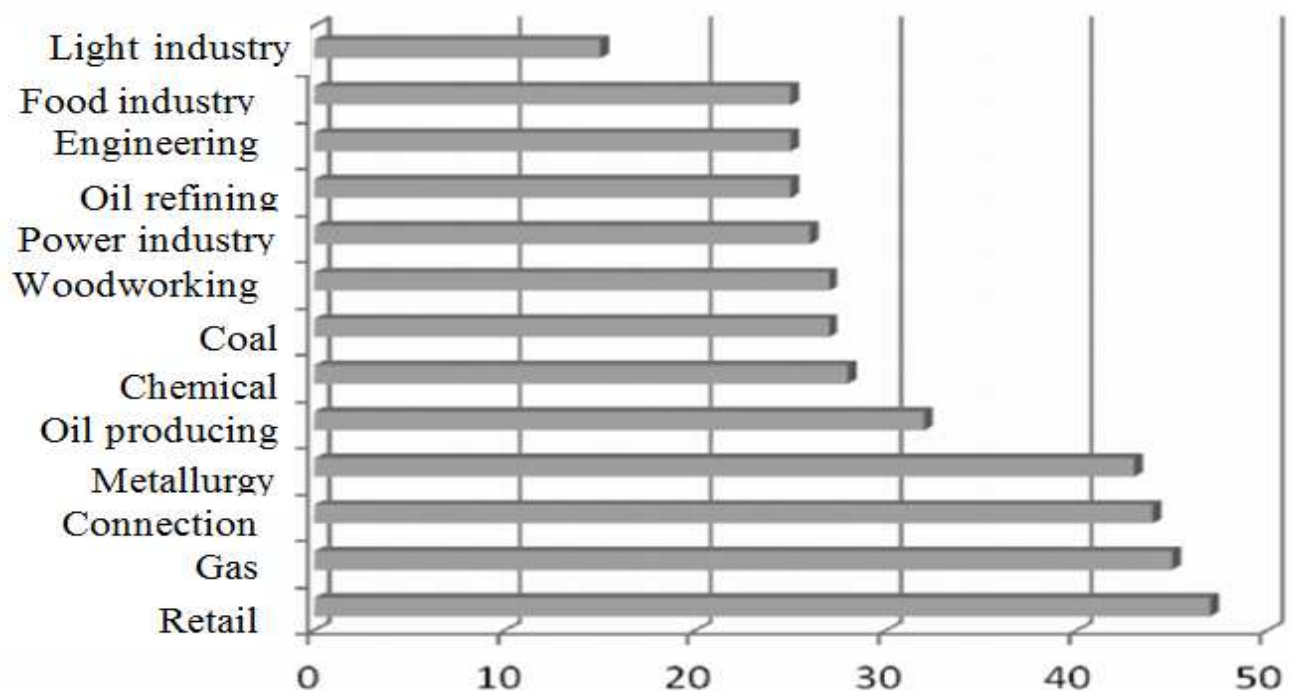

Fig. 2. Score rating of investment attractiveness of industries [3].

Analyzing the degree of riskiness of the electric power industry, one should also take into account the measures introduced at the level of the Russian Federation and the Republic of Tatarstan.

\section{Results And Discussion}

According to a study conducted by Ernst \& Young regarding the riskiness of 12 different industries [6], the result of which was a list of the TOP 10 business risks most affecting the selected industries (Fig. 1), we can conclude that the electricity industry The Russian Federation is extremely strongly influenced by energy crises and radical greening. In turn, radical greening is manifested in the tightening of legislative and tax requirements in the field of environmental protection, as well as in the change in consumer demand towards more environmentally friendly products.

As a result of the analysis carried out by FINAM analysts, it can be seen that the electricity industry turned out to be in 7 th place as the investment attractiveness of organizations with a rating of 27 out of 50 decreased. Thus, the electricity industry has a low degree of investment attractiveness. Accordingly, there is a lack of investment in the industry, which can lead to serious problems in the future.

Having studied the statistics of bankruptcies of electric power enterprises of the Russian Federation, we 
came to the conclusion that the dynamics of bankruptcies indicates a low risk industry in this context, since the dynamics is increasingly negative compared to previous years (Fig. 3).

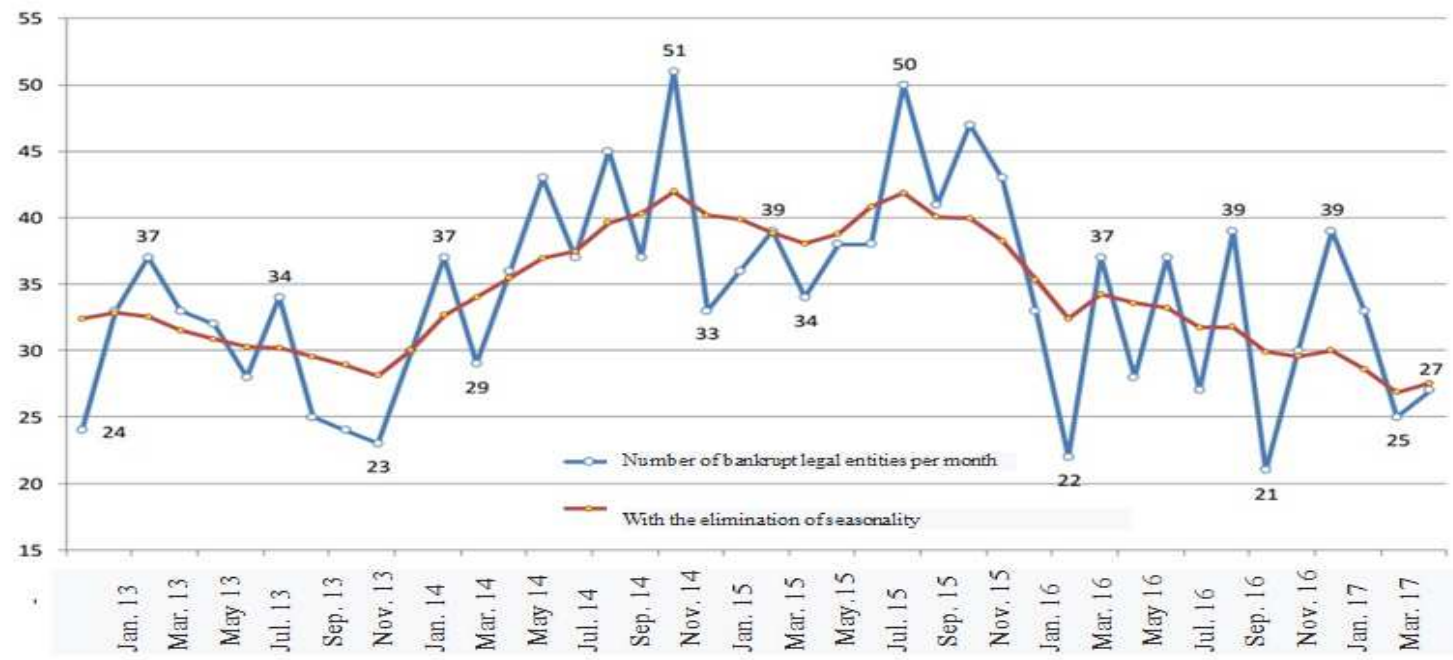

Fig. 3. The dynamics of the number of bankruptcies in the electricity industry [1].

If we pay attention to Federation, the electric power industry comparing the number of bankruptcies does not show the highest rates (Fig. 4). among the main sectors of the Russian

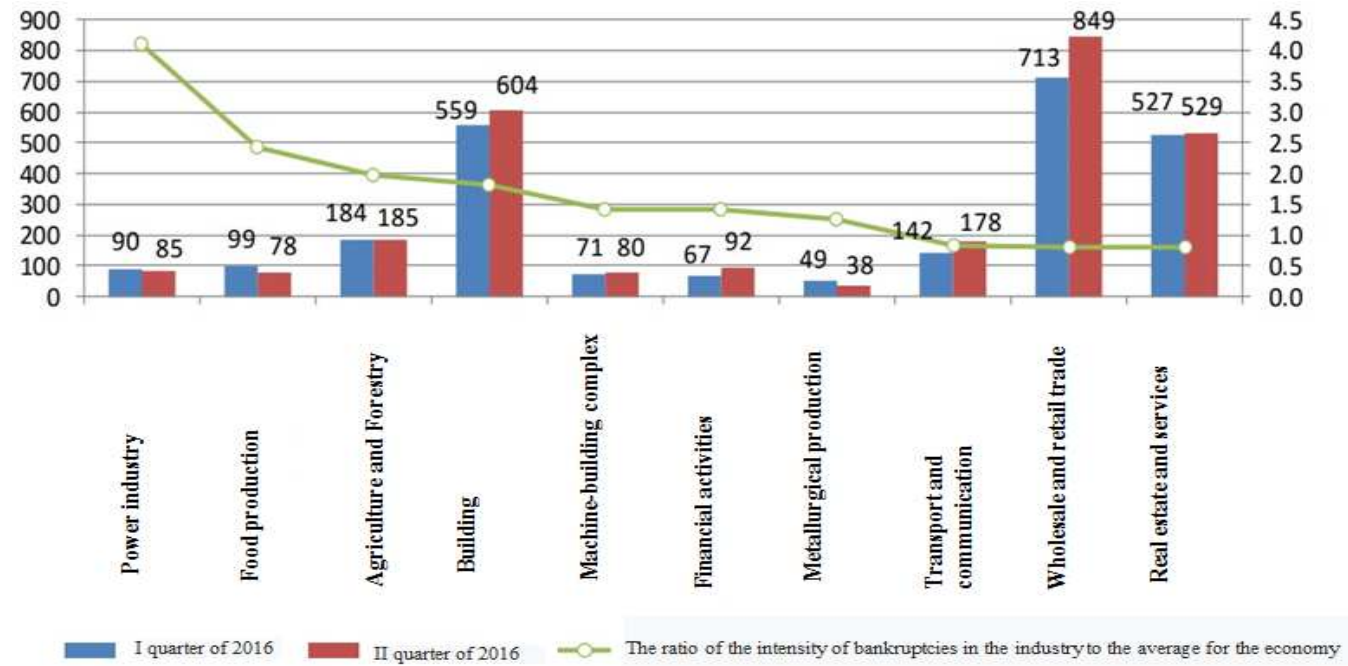

Fig. 4. The number of bankruptcies in industries for 2016 [1]. 
In total, in 2016 the number of bankruptcies in the electric power industry of the Russian Federation amounted to 175 . For example, the largest number of bankruptcies is in wholesale and retail trade (1562), and the smallest number is in metallurgical production (87). The number of bankruptcies of almost all analyzed sectors increased to a greater extent in the second quarter of 2016, which is associated primarily with the stagnation of investment in fixed assets [1].

An analysis of the measures being implemented at the level of the Russian Federation and the Republic of Tatarstan showed that the electric power industry in Russia underwent a number of significant changes in the framework of the previous program "Energy Strategy of Russia" [8], developed from 2003 to 2020, namely, the system of state regulation and the structure changed industry as a whole, a competitive market for electricity and capacity has formed. The process of reforming the Russian electric power industry was carried out with the aim of attracting additional investments to modernize the industry and increase its efficiency. Private investments that were attracted
342

as a result of this process significantly increased the size of the reserve capacity of the Russian energy system.

In order to further reform and improve the efficiency of the electric power industry, the Government of the Russian Federation has developed the Energy Strategy of Russia for the period until 2035 [9]. First of all, this is due to a number of factors: the geopolitical crisis of 2014, the introduction of financial and technological sanctions against Russia by a number of countries, the volatility of world energy prices and the tightening of global competition for resources.

According to the above document, the goal of the energy strategy is to ensure a qualitatively new state of the Russian energy sector, which maximally contributes to its dynamic development. The energy strategy also involves fulfilling the tasks of providing the country with energy products and services in terms of volume, nomenclature and quality, which can guarantee the country's energy security and the reliability of the energy production structure.

The next task is to improve the territorial and production structure of the fuel and energy complex, which is the 
basis for the harmonious energy development of the Russian regions, the creation of new fuel and energy and energy industrial complexes that imply stimulation of the development of Russian regions, the use of local energy resources and renewable energy sources. The challenges also include stimulating innovative import substitution, developing the national market for hightech products and technologies, increasing the technological competitiveness of the Russian fuel and energy complex, up to Russia's active participation in shaping global technology trends, which, ultimately, will be aimed at ensuring technological independence of the Russian energy sector.

As you know, one of the main factors of the low level of efficiency of RF power plants is a significant share of outdated energy equipment. In addition, inadequate investments aimed at updating fixed assets, as well as their reconstruction and modernization may be the causes of technical constraints and reduce the reliability of energy supply to consumers. Thus, a very acute problem is the physical and moral obsolescence of electric power equipment, which poses a threat to Russia's energy security. In this case, the situation can be remedied by decommissioning outdated infrastructure and large-scale investments in new effective capacities. All these measures will increase the competitiveness and efficiency of domestic energy companies, improve the environmental characteristics of the industry, and reduce the risk of accidents [7].

In this study, as an example of competent handling of risk factors for the functioning of the company, an analysis of the risk management system implemented in the energy company Pyc PJSC RusHydro is presented. To reduce the negative impact of potential dangers and realize favorable opportunities, PJSC RusHydro has created a risk management system that aims to ensure the implementation of the company's development strategy. To organize risk management processes at this enterprise, a Risk Control and Management Department was created as part of the internal control and risk management unit. The corporate risk management system of this company is presented in Figure 5. 


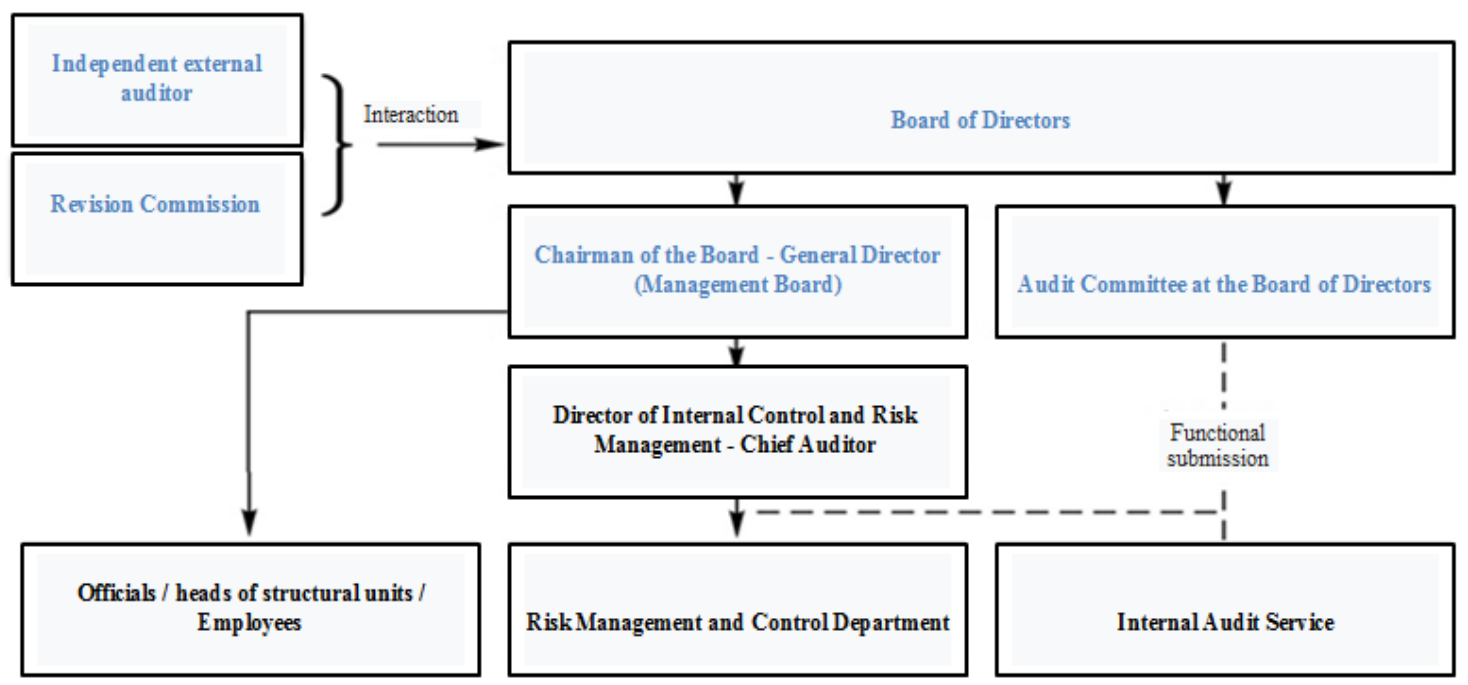

Fig. 5. Corporate risk management system of PJSC RusHydro [2].

A comprehensive assessment of the effectiveness of the internal control and risk management system is carried out by invited independent experts. Also, the quality of the risk management system of PJSC RusHydro is regularly confirmed by an independent jury of international competitions.

As for the identification of risks, it is carried out on the basis of analysis of external information, the experience of the world's largest companies in the electric power industry, reports of consulting and insurance companies on the risks of companies in the fuel and energy complex and business as a whole. Among the most significant for the company should be noted the growth of the following risks: the risk of failure to achieve targets by engineering companies, as well as the risk of an increase in receivables for the supply of electricity and capacity. At the same time, during the period under review, the relevance of risks associated with personnel management has significantly decreased. The register of risks identified by PJSC RusHydro is presented in Figure 6. 


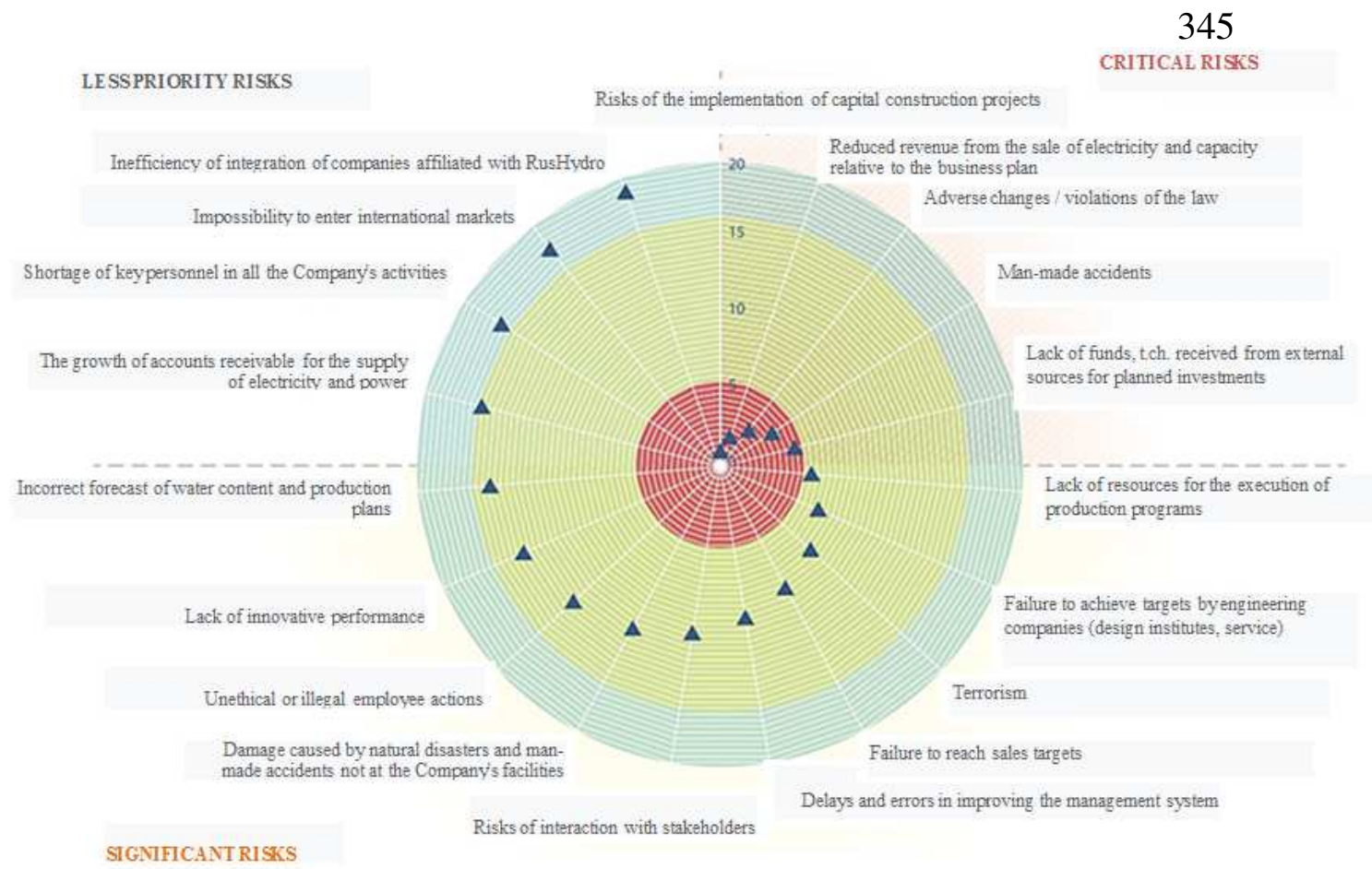

Fig. 6. Risk Radar of PJSC RusHydro for 2016-2017 [2].

In PJSC RusHydro, this register is compiled annually and for each risk the owner is determined, which is approved by the Management Board of the company. For risks that fall into the category of critical and significant, the Board approves a strategic risk management action plan that defines the terms, responsible and expected results. Monitoring the implementation of the plan and monitoring its implementation is carried out by risk managers of the company [2].

It should be noted that the risk management system of this company is based on the provisions of the ISO 31000 standard, which, accordingly, allows you to comprehensively assess, monitor, calculate all types of risks, manage them both at the strategic and operational levels, as well as implement a full reporting collection cycle about the risks. This risk management mechanism is an in-house development of PJSC RusHydro, which was put into commercial operation in 2014. The main feature of the program is the presence of the RiskReport module.

This module allows you to quickly collect information about risks and create a "Risk Map", including an assessment of the worst-case scenarios, 
and also makes it possible to analyze each risk [5]. Ultimately, a professional approach to risk management enables this company to survive in a competitive environment. We believe that the experience of PJSC RusHydro can be used as an example of the implementation of risk management for other electric power enterprises of the Russian Federation.

\section{Summary}

Thus, having analyzed production indicators, we can say that the electric power industry in Russia is at the stage of its active development. The further success of these transformations will be largely determined by the timeliness and completeness of providing the industry with investments and advanced technologies.

As for the Republic of Tatarstan, it can be stated with full confidence that the electric power industry is the basic industry for the entire economy of the republic. The welfare of the population, the competitiveness and profitability of industrial enterprises, and, accordingly, the general level of socio-economic development of the region directly depend on its effectiveness. The basis of the region's electric power complex are: Generation Company OJSC, Tatenergo OJSC, Tatenergo Regional Dispatch Management CJSC, Network Company OJSC, Energosbyt enterprise, republic heating network enterprises and other profile power system structures. The production of electric energy in the Republic of Tatarstan is mainly based on thermal power plants (91-92\%) [4].

Despite these advantages of the electric power industry of the Republic of Tatarstan, there are problems that require special attention:

- high physical and moral depreciation of fixed assets (52.8\%), which is explained by the rather low investment attractiveness of the energy sector, the need for significant capital investments;

- focus on one type of fuel (natural gas), the dependence of consumers on gas supplies from outside the country;

- significant environmental impact on the environment [4].

\section{Conclusions}

As you can see, the risky nature of the industry is confirmed both at the 
federal and republican levels. However, the high riskiness of the type of activity requires the active implementation of risk exposure mechanisms. Over the past 10-15 years, a professional approach to risk management has been confidently introduced in the Russian Federation. And although risk management has only just begun to gain momentum in Russia and is not used at all Russian enterprises, its use uniquely positively and efficiently affects the organization's activities and contributes to its survival in the market. Thus, the risk management system, as part of business management, is gradually finding its place in Russian energy companies, which positively affects their success and reaching the level of world organizations.

\section{Acknowledgements}

The work is performed according to the Russian Government Program of Competitive Growth of Kazan Federal University.

\section{Bibliography}

Bankruptcies of legal entities in Russia: main trends. Electronic resource // Access

mode:
http://www.forecast.ru/_ARCHIVE/Ana litics/PROM/2016/Bnkrpc-2-16.pdf

Annual report of PJSC RusHydro for 2016. Electronic resource // Access mode:

http://fs.moex.com/content/annualreport s/5108/1/go-pao-rusgidro-za-2016-

god.pdf

The investment attractiveness of the branches of the Russian economy. Electronic resource // Access mode: http://www.publishing-

vak.ru/file/archive-economy-2016-7/2$\underline{\text { tarelkin.pdf }}$

The main trends in the development of the electric power complex of the Republic of Tatarstan. Electronic resource // Access mode: https://bgscience.ru/lib/10661/

RusHydro risk management program. Electronic resource // Access mode: https://minenergo.gov.ru/node/2307

"TOP 10 business risks". Electronic resource // Access mode: http://hrportal.ru/article/top-10-biznes-riskov- 
Electric power industry in Russia: problems and strategic directions of development of the industry. Electronic resource // Access mode: http://www.publishing-

vak.ru/file/archive-economy-2016-9/10duskabilova.pdf

The energy strategy of Russia for the period until 2020. Electronic resource // Access mode: http://www.rosteplo.ru/Npb_files/npb_s hablon.php?id=25

Russia's energy strategy for the period until 2035. Electronic resource // Access mode:

http://budget.open.gov.ru/upload/iblock/ e72/e7292e1bd8baa850b6ada59144730 001.pdf

Ernst \& Young: 10 key risks and opportunities for companies in the fuel and energy sector and the electric power industry. Electronic resource // Access mode:

http://www.oilru.com/news/366065 